\title{
BMJ Open Expanding access to high-cost medicines through the E2 access program in Thailand: effects on utilisation, health outcomes and cost using an interrupted time-series analysis
}

\author{
Rosarin Sruamsiri, ${ }^{1,2}$ Anita K Wagner, ${ }^{2}$ Dennis Ross-Degnan, ${ }^{2}$ Christine $\mathrm{Y} \mathrm{Lu},{ }^{2}$ \\ Teerapon Dhippayom, ${ }^{3}$ Surachat Ngorsuraches, ${ }^{4}$ Nathorn Chaiyakunapruk ${ }^{1,5,6,7}$
}

To cite: Sruamsiri R, Wagner AK, Ross-Degnan D, et al. Expanding access to high-cost medicines through the E2 access program in Thailand: effects on utilisation, health outcomes and cost using an interrupted time-series analysis. $B M J$ Open 2016;6:e008671. doi:10.1136/bmjopen-2015008671

- Prepublication history and additional material is available. To view please visit the journal (http://dx.doi.org/ 10.1136/bmjopen-2015008671)

Received 7 May 2015 Revised 23 December 2015 Accepted 15 February 2016

CrossMark

For numbered affiliations see end of article.

Correspondence to Professor Nathorn Chaiyakunapruk; nathorn.chaiyakunapruk@ monash.edu

\section{ABSTRACT}

Objective: In 2008, the Thai government introduced the 'high-cost medicines E2 access program' as a part of the National List of Essential Medicines to increase patient access to medicines, improve clinical outcomes and make medicines more affordable. Our objective was to examine whether the 'high-cost medicines E2 access program' achieved its goals.

Design: Interrupted time-series design study.

Setting: 3 tertiary hospitals in different regions of Thailand, January 2006 to December 2012.

Participants: Patients with target acute and chronic disease diagnoses who newly met E2 program criteria for selected study medicines.

Intervention: High-cost medicines E2 access program.

Main outcomes measures: Level and trend changes over time in the proportions of eligible patients who received the indicated E2 medicines and who improved clinically, as well as in costs of treatment.

Results: A total of 2024 patients were included in utilisation analyses and 1375 patients with selected acute diseases contributed to analyses of clinical outcome. After 1 year of the E2 program implementation, the percentage of eligible patients receiving the indicated E2 program medicines increased significantly (relative change $12.7 \%(95 \% \mathrm{Cl}$ $4.4 \%$ to $21.0 \%$ ), especially among those insured by the government's universal coverage scheme (relative change $19.9 \%(95 \% \mathrm{Cl} 9.5 \%$ to $30.5 \%))$. The increase in the proportion of clinically improved patients with acute conditions was not significant (relative change $6.2 \%(95 \% \mathrm{Cl}-1.9 \%$ to $15.1 \%))$. Quarterly healthcare costs per patient dropped significantly (relative change $-13.5 \%(95 \% \mathrm{Cl}-26.9 \%$ to $-1.7 \%))$.

Conclusions: In the study hospitals, the E2 access program seems to have facilitated patient access to specialty medicines, may have contributed to improved health outcomes, and decreased treatment costs. Routine monitoring is needed to assess effects of expanding the programme, including effects on quality of care and financial sustainability.

\section{Strengths and limitations of this study}

- This is the first longitudinal study that evaluates a Thai government policy (the E2 high-cost medicines access program) to provide coverage for high-cost specialty medicines by introducing a new subcategory in the National List of Essential Medicines (NLEM): the E2 category of high-cost medicines for specific conditions.

- This study evaluated all programme goals. We found that the E2 program was associated with an increasing number of patients receiving specialty medicines and may have improved selected clinical outcomes, especially among universal coverage patients who constitute the majority of the Thai population.

- There were substantial decreases both in treatment cost per patient and annual healthcare expenditures after E2 policy implementation, mainly due to decreases in E2 medicines prices. We speculate that pooled procurement of bulk volumes and special purchasing arrangements with the companies resulted in lower prices.

- The study was limited to three hospitals only and short-term clinical outcomes could only be assessed for selected conditions.

- Routine monitoring will be needed to assess effects of expanding the E2 access program to more medicines, including effects on quality of care and financial sustainability.

\section{INTRODUCTION}

Novel specialty medicines provide hope for patients with cancers, autoimmune disorders and other serious conditions, but because of their high costs, use of specialty medicines presents economic challenges to households and healthcare systems. These challenges are magnified in low and middle income countries where healthcare systems are under-resourced and access to specialised 
healthcare services is limited. ${ }^{1}$ To ensure effective use of resources, policymakers should aim to target access to specialty medicines to those who can benefit from them clinically and monitor whether clinical outcomes improve as expected.

Like many countries, Thailand, an upper-middle income country in South-East Asia, seeks to contain growing healthcare expenditures while enabling access to innovative high-cost medicines. Healthcare expenditures in Thailand rose from US $\$ 7032$ million in 2002 to US\$13 182 million in $2013 .^{2}$ At $7.8 \%$ per year, healthcare expenditures have grown faster than the gross domestic product (GDP, 5.8\%). ${ }^{3}$ Since 2006, medicines have constituted approximately $46 \%$ of healthcare expenditures $^{3}$ compared with $18 \%$ in countries of the Organisation for Economic Co-operation and Development (OECD). ${ }^{4}$

Under universal health coverage (UHC) implemented in 2002, all Thais belong to one of three main health insurance schemes: the Civil Servant Medical Benefit Scheme (CSMBS) for government employees $(7.6 \%$ of the population in 2013), the Social Security Scheme (SSS) for private sector employees $(16.1 \%)$, and the Universal Coverage (UC) Scheme $(76.3 \%)$ for those not enrolled in CSMBS or SSS. ${ }^{5}$ Each scheme guarantees access to a basic benefit package of health services, including medicines listed on the National List of Essential Medicines (NLEM). ${ }^{6}$ However, the schemes differ with respect to medicines not on the NLEM, some of which are high-cost specialty medicines. UC Scheme and SSS enrollees pay out of pocket (OOP) for all non-NLEM medicines; for CSMBS patients, most NLEM and non-NLEM medicines are free of charge and providers receive fee-for-service payments. ${ }^{7}$ Thus, more than $90 \%$ of the Thai population pays OOP for non-NLEM medicines. The government addressed this challenge through a multipronged strategy known as the high-cost medicines E2 access program ('E2 program'), which was introduced with the 2008 NLEM revision. ${ }^{8}{ }^{9}$ The E2 program mandated all three insurance schemes to subsidise selected high-cost specialty medicines for patients meeting eligibility criteria. The E2 program aimed to increase access to high-cost medicines for treating rare or complex conditions. By increasing access to these medicines, the E2 program aims to improve clinical outcomes while ensuring affordability of the treatments for individuals and the health system. ${ }^{9}$ Initially, the programme covered 10 specialty medicines (botulinum A toxin, docetaxel, erythropoietin $\alpha$, erythropoietin $\beta$, letrozole, leuprorelin acetate, liposomal amphotericin B, human IgG, imatinib and verteporfin) for 21 indications. Patients eligible for each E2 program medicine must meet specific clinical criteria set by the National Drug Committee ${ }^{9}$ and be treated by specialist clinicians registered with the government.

The Thai government allowed each insurance scheme to implement coverage required by the E2 program over time. The National Health Security Office (NHSO) started covering E2 medicines for UC enrollees in January 2009; the Social Welfare Office (SWO) did so 3 years later (July 2012) for SSS enrollees. Enrollees in the CSMBS scheme continued to receive the medicines without charge under their fee-for-service benefit. ${ }^{10}$ For both UC Scheme and SSS enrollees, costs of care and medicines are covered through fixed capitation amounts for outpatient visits and case-based payments for hospital care. Providers had no financial incentive to prescribe E2 program medicines but facilities needed to make sure that reimbursed amounts covered the costs, which led to limited access while the products were initially listed in 2008 NLEM. In January 2009, the NHSO collaborated with the Government Pharmaceutical Organization (GPO) to introduce central procurement for all E2 medicines used for UC patients instead of individual hospitalbased procurement. Pooled procurement resulted in lower prices of high-cost E2 medicines. ${ }^{11}$ Whenever healthcare providers give UC patients an E2 medicine, the GPO will distribute these medicines directly to hospitals via a vendor-managed inventory system. For SSS enrollees, hospitals can purchase medicines directly from pharmaceutical companies at centrally negotiated prices.

Although the E2 program had operated in Thailand for almost 6 years by 2014, there remained a lack of knowledge about whether it has achieved its objectives. The purpose of this study was to assess whether the E2 program has expanded access to selected high-cost medicines, improved health outcomes, and reduced total healthcare expenditures for the Thai population, particularly for UC patients, in three study hospitals.

\section{METHODS}

We conducted a retrospective interrupted time-series study in three hospitals in different regions of Thailand (1 tertiary care regional hospital and 2 university hospitals).

\section{Data sources}

We extracted utilisation and billing data of inpatient, outpatient, pharmacy and laboratory services from hospital electronic databases; we also abstracted clinical information from hospital records using standardised data collection forms. We extracted data between 1 January 2006 and 31 December 2012 and disaggregated them by quarter. We excluded cancer medicines (letrozole, docetaxel and imatinib) and erythropoietin because other programmes implemented during and prior to the study period had targeted access to these medicines (ie, compulsory licensing for cancer medicines in $2007^{12}$ and Kidney Foundation support for patients with end-stage renal disease in 2002).

\section{Patient identification}

From electronic hospital database records, we identified patients who had at least two diagnoses with an International Classification of Diseases, 10th Revision 
(ICD-10) code for 1 or more of the 13 indications for five selected E2 medicines (intravenous immunoglobulin (IVIG), leuprorelin, liposomal amphotericin B, verteporfin and botulinum A toxin) during the study period. Then we assessed whether the included patients were eligible for the respective E2 medicine. The E2 program specified patient eligibility criteria by clinical/laboratory results and prior treatment history, which were developed on the basis of the literature and clinician inputs. Online supplementary appendix 1 lists the eligibility criteria for treatment with E2 medicines, including ICD-10 codes, laboratory results, clinical conditions and medications used. Study patients were those who met all clinical criteria for access to E2 medicines at the index visit, including any requirements for prior medication use and no evidence of receiving an E2 medicine in the year prior to the index visit, as judged by two chart reviewers (RS and a research nurse at each hospital).

\section{Study outcome measures}

Among patients newly eligible for E2 medicines in each quarter, we examined access to selected E2 medicines, clinical outcomes and healthcare costs. ${ }^{8}$ We evaluated study outcomes at the end of the first index hospitalisation for inpatient cases.

First, we measured utilisation as a proxy for access ${ }^{13}$; we calculated the quarterly percentage of newly eligible patients who received the indicated E2 medicines.

Second, we measured clinical outcomes that would be expected to change within the index hospitalisation for patients with acute conditions, which accounted for $70 \%$ of total cases in the study. Clinical experts (in haematology, neurology, immunology and infectious disease) defined criteria for judging improvements of eight conditions treated by two E2 medicines (IVIG and liposomal amphotericin B) based on laboratory test results, procedures and/or clinical symptoms (see online supplementary appendix 2). We (RS and a research nurse at each hospital) reviewed the charts of patients to assess whether patients had improved clinical outcomes as defined by experts' criteria. We calculated the quarterly percentage of eligible patients with improvements (table 1).

Finally, we measured median healthcare costs per patient, both quarterly and annually. Costs were calculated for medicines, laboratory tests, medical services and other services by converting hospital charges recorded in electronic billing databases to costs using a cost-to-charge ratio of $0.73 .{ }^{14}$ All costs were reported in 2014 US Dollar (US $\$ 1=31.08$ Thai Baht $(\mathrm{THB}))^{15}$ and adjusted using the Consumer Price Index (CPI) ${ }^{16}$ We separately calculated medicine expenditures (E2 medicines and non-E2 medicines) and other healthcare costs. Since NHSO initiated pooled procurement and supplied E2 medicines directly to hospitals (resulting in the hospital databases) as part of the implementation of the E2 program, we used central GPO procurement prices as E2 medicines prices for UC patients. ${ }^{17}$

\begin{tabular}{|c|c|c|}
\hline Characteristics & $\begin{array}{l}\text { Before } 2009 \text { E2 } \\
\text { implementation } \\
(2007-2008)\end{array}$ & $\begin{array}{l}\text { After } 2009 \text { E2 } \\
\text { implementation } \\
(2009-2012)\end{array}$ \\
\hline $\mathrm{N}$ & $574(28 \%)$ & $1450(72 \%)$ \\
\hline Age (mean $\pm S D)$ & $33.64 \pm 26.33$ & $34.14 \pm 26.90$ \\
\hline $0-15$ years & $205(36 \%)$ & $498(34 \%)$ \\
\hline $16-30$ years & $57(10 \%)$ & $157(11 \%)$ \\
\hline $31-45$ years & $59(10 \%)$ & $165(11 \%)$ \\
\hline $46-60$ years & $115(20 \%)$ & $294(20 \%)$ \\
\hline$>60$ years & $138(24 \%)$ & $336(23 \%)$ \\
\hline \multicolumn{3}{|l|}{ Gender } \\
\hline Female & $291(51 \%)$ & $734(51 \%)$ \\
\hline \multicolumn{3}{|l|}{ Health insurance* } \\
\hline CSMBS & $112(20 \%)$ & $335(23 \%)$ \\
\hline SSS & 120 (21\%) & $51(4 \%)$ \\
\hline UC & 308 (54\%) & $1001(69 \%)$ \\
\hline Others & $34(6 \%)$ & $63(4 \%)$ \\
\hline \multicolumn{3}{|c|}{ Charlson Comorbidity Index } \\
\hline $0-1$ & $371(65 \%)$ & $921(64 \%)$ \\
\hline $2-3$ & $157(27 \%)$ & $387(27 \%)$ \\
\hline$>3$ & $44(8 \%)$ & $142(10 \%)$ \\
\hline \multicolumn{3}{|l|}{ Patients eligible for } \\
\hline Botulinum $A$ toxin & $57(10 \%)$ & $167(12 \%)$ \\
\hline IVIG & 367 (64\%) & $942(65 \%)$ \\
\hline Leuprorelin & $66(11 \%)$ & $131(9 \%)$ \\
\hline $\begin{array}{l}\text { Liposomal } \\
\text { amphotericin B }\end{array}$ & $44(8 \%)$ & $102(7 \%)$ \\
\hline Verteporfin & $40(7 \%)$ & $108(7 \%)$ \\
\hline \multicolumn{3}{|c|}{$\begin{array}{l}\text { Study patients: patients who had at least two admissions or visits } \\
\text { during the study period, met the eligibility criteria for an E2 } \\
\text { medicine, and who had not received an E2 medicine } 1 \text { year prior } \\
\text { to their index visit. } \\
\text { *p<0.05. } \\
\text { CSMBS, Civil Servant Medical Benefit Scheme; SSS, Social } \\
\text { Security Scheme. }\end{array}$} \\
\hline
\end{tabular}

\section{Statistical analysis}

The E2 program was announced in March 2008 and formally implemented for UC patients in January 2009 and SSS patients in July 2012. The focus of our analyses was on all patients eligible for E2 medicines including patients insured by three health insurance schemes (CSMBS, SSS and UC Scheme programmes). We also conducted a subgroup analysis with a specific focus on UC patients who were targeted by the E2 program in 2009. We defined two distinct periods: 8 quarters before implementation of the E2 program (2007Q1-2008Q4) and 14 quarters postimplementation (2009Q3-2012Q3). To account for a possible lag in the E2 program taking effect, we defined 2009Q1-2009Q2 as an intervention phase-in period. ${ }^{18}$

We conducted segmented regression analyses of the time-series data correcting for autocorrelated errors using the STATA arima command to estimate the effects of the E2 program. ${ }^{19}$ This method allows us to account for baseline levels and trends in each outcome measure while assessing changes in levels and trends following E2 implementation. We assessed whether key population 
characteristics that could have affected the outcomes changed at the time of the policy. ${ }^{20}$ We compared patient characteristics in the pre-E2 and post-E2 program implementation periods using $\chi^{2}$ tests and analyses of variance, and also assessed longitudinal patterns of each characteristic. We found no significant discontinuities in patient age, gender or Charlson Comorbidity Index during the study period. We therefore did not perform adjusted analyses. Since we used aggregated time-series data at the population level, our results were not affected by clustering. ${ }^{18}$

We estimated absolute and relative differences (with 95\% CIs) in observed versus predicted (based on baseline levels and trends) outcome values at 1 and 2 years post-E2 policy implementation. ${ }^{21}$ In sensitivity analyses, we excluded three quarterly data points during the policy roll-out period from our regression models and ran models that eliminated terms with $p>0.20$. We also performed subgroup analyses for UC patients. All analyses were performed in STATA V.12.0.

\section{RESULTS}

Between 1 January 2006 and 31 December 2012, we identified 33456 patients in the three hospitals who had ICD-10 codes for indications of the E2 medicines.
A total of 31432 patients were excluded due to incomplete data $(12 \%)$, not meeting eligible criteria for the E2 program $(85 \%)$, and for receiving an E2 medicine within 1 year prior to the index visit date $(3 \%)$. A total of 2024 new patients were included in the utilisation and cost analyses and 1375 (68\%) with an acute condition were eligible for clinical outcomes measurement (figure 1). Patient characteristics are shown in table 1 and results for each outcome are shown in table 2 . Thirty-four per cent of eligible patients came from a university hospital in Bangkok, $41 \%$ from a university hospital in Chiang Mai and 25\% from a hospital in Phitsanulok.

\section{Utilisation}

Overall, about two-thirds of eligible patients received E2 medicines at the start of the observation period. In figure $2 \mathrm{~A}$, the percentage of eligible patients receiving E2 medicines showed a significant change in level immediately after the implementation of the E2 program (level change $9.8 \%$ (95\% CI $6.8 \%$ to $12.8 \%$ )) and a decrease in the trend of $0.2 \%$ (95\% CI $-0.7 \%$ to $0.3 \%)$, resulting in estimated increases of $12.7 \%$ (95\% CI $4.4 \%$ to $21.0 \%$ ) and $11.5 \%$ (95\% CI $0.3 \%$ to $22.7 \%$ ) in the number of eligible patients receiving E2 medicines 1 and 2 years after the E2 program implementation,
Figure 1 Patient selection for utilisation, clinical outcome and cost measurement. ICD-10, International Classification of Diseases, 10th Revision.

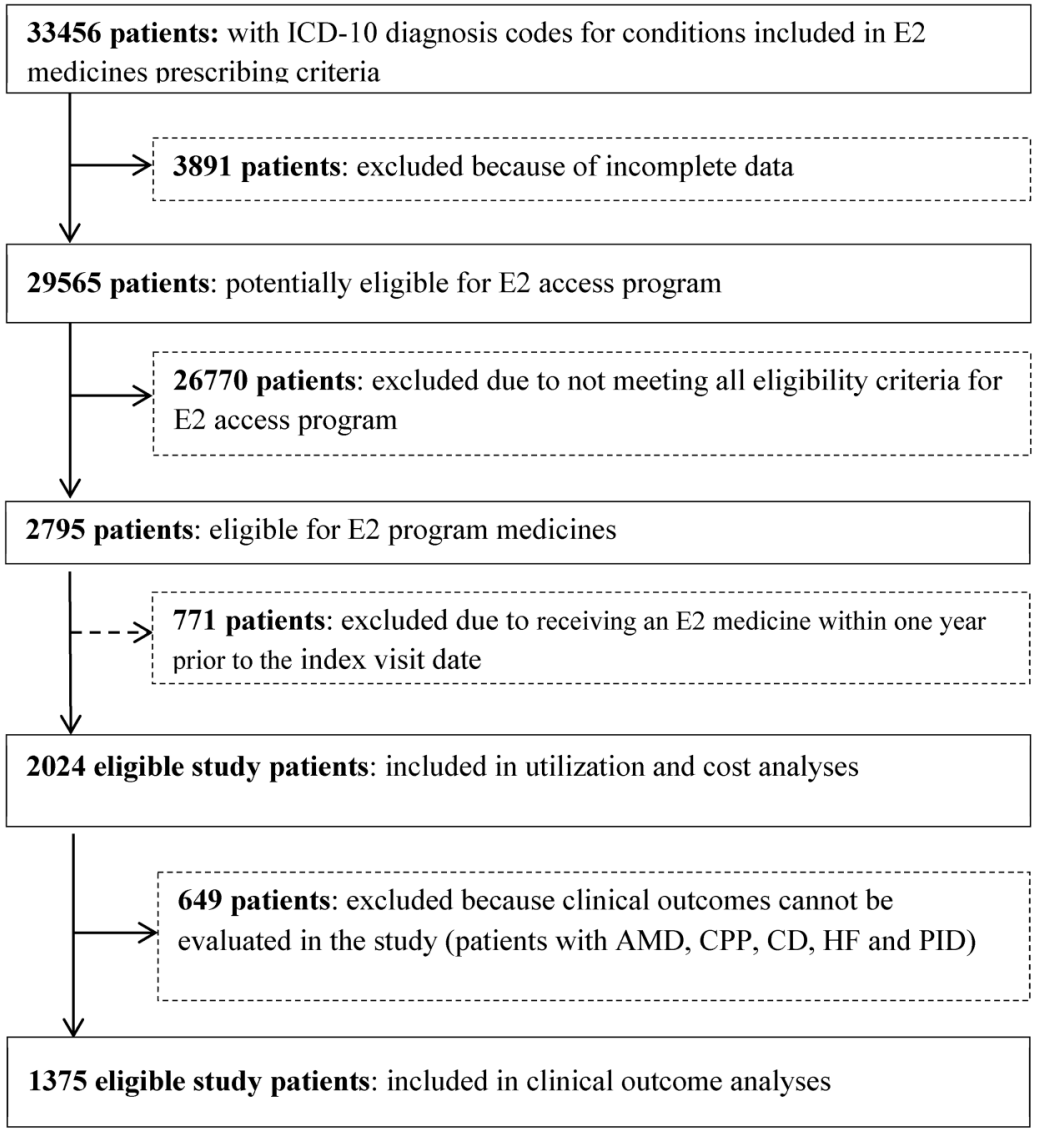

AMD: age-related macular degeneration; CPP: central precocious puberty; CD: cervical dystonia; $\mathrm{HF}$ : hemifacial spasm; PID: primary immune deficiency disease 
Table 2 Estimates of baseline trend, level and trend changes, absolute and relative changes in utilisation, clinical outcomes and healthcare costs per patient following the E2 access program

\begin{tabular}{|c|c|c|c|c|c|c|c|}
\hline \multirow[b]{2}{*}{$\begin{array}{l}\text { Impact of } \\
\text { policy }\end{array}$} & \multirow[b]{2}{*}{$\begin{array}{l}\text { Quarterly baseline } \\
\text { trend prepolicy } \\
(95 \% \mathrm{Cl})\end{array}$} & \multirow[b]{2}{*}{$\begin{array}{l}\text { Level change } \\
\text { postpolicy }(95 \% \mathrm{Cl})\end{array}$} & \multirow[b]{2}{*}{$\begin{array}{l}\text { Quarterly trend } \\
\text { change postpolicy } \\
\text { (95\% Cl) }\end{array}$} & \multicolumn{2}{|c|}{ At 1 year after E2 implementation } & \multicolumn{2}{|c|}{ At 2 years after E2 implementation } \\
\hline & & & & $\begin{array}{l}\text { Absolute change } \\
(95 \% \mathrm{Cl})\end{array}$ & $\begin{array}{l}\text { Relative change } \\
(95 \% \mathrm{Cl})\end{array}$ & $\begin{array}{l}\text { Absolute change } \\
(95 \% \mathrm{Cl})\end{array}$ & $\begin{array}{l}\text { Relative change } \\
(95 \% \mathrm{Cl})\end{array}$ \\
\hline \multicolumn{8}{|l|}{ All patients } \\
\hline Utilisation & $\begin{array}{l}0.1 \% \\
(-0.4 \% \text { to } 0.6 \%)\end{array}$ & $\begin{array}{l}9.8 \% \\
(6.8 \% \text { to } 12.8 \%)\end{array}$ & $\begin{array}{l}-0.2 \% \\
(-0.7 \% \text { to } 0.3 \%)\end{array}$ & $\begin{array}{l}8.7 \% \\
\text { (3.5\% to } 13.9 \%)\end{array}$ & $\begin{array}{l}12.7 \% \\
(4.4 \% \text { to } 21.0 \%)\end{array}$ & $\begin{array}{l}8.0 \% \\
(1.0 \% \text { to } 14.9 \%)\end{array}$ & $\begin{array}{l}11.5 \% \\
(0.3 \% \text { to } 22.7 \%)\end{array}$ \\
\hline Outcomes & $\begin{array}{l}0.05 \% \\
(-0.4 \% \text { to } 0.5 \%)\end{array}$ & $\begin{array}{l}5.4 \% \\
(2.0 \% \text { to } 8.7 \%)\end{array}$ & $\begin{array}{l}-0.06 \% \\
(-0.6 \% \text { to } 0.5 \%)\end{array}$ & $\begin{array}{l}5.0 \% \\
(-1.1 \% \text { to } 11.1 \%)\end{array}$ & $\begin{array}{l}6.6 \% \\
(-1.9 \% \text { to } 15.1 \%)\end{array}$ & $\begin{array}{l}4.8 \% \\
(-3.3 \% \text { to } 12.8 \%)\end{array}$ & $\begin{array}{l}6.2 \% \\
(-5.0 \% \text { to } 17.5 \%)\end{array}$ \\
\hline Costs & $\begin{array}{l}\$ 56.39 \\
(-\$ 61.96 \text { to } \$ 174.73)\end{array}$ & $\begin{array}{l}-\$ 687.10 \\
(-\$ 1534.65 \text { to } \\
\$ 160.44)\end{array}$ & $\begin{array}{l}-\$ 94.42 \\
(-\$ 220.76 \text { to } \$ 31.91)\end{array}$ & $\begin{array}{l}-\$ 1253.66 \\
(-\$ 4756.70 \text { to } \\
\$ 176.85)\end{array}$ & $\begin{array}{l}-13.5 \% \\
(-26.9 \% \text { to }-0.2 \%)\end{array}$ & $\begin{array}{l}-\$ 1631.37 \\
(-\$ 3520.85 \text { to } \\
\$ 258.66)\end{array}$ & $\begin{array}{l}-17.2 \% \\
(-33.7 \% \text { to }-0.7 \%)\end{array}$ \\
\hline \multicolumn{8}{|l|}{ UC patients } \\
\hline Utilisation & $\begin{array}{l}-0.4 \% \\
(-0.1 \% \text { to } 0.9 \%)\end{array}$ & $\begin{array}{l}14.5 \% \\
(11.8 \% \text { to } 17.2 \%)\end{array}$ & $\begin{array}{l}-0.3 \% \\
(-0.9 \% \text { to } 0.2 \%)\end{array}$ & $\begin{array}{l}12.4 \% \\
\text { (6.8\% to } 18.0 \%)\end{array}$ & $\begin{array}{l}19.6 \% \\
(9.1 \% \text { to } 30.3 \%)\end{array}$ & $\begin{array}{l}11.0 \% \\
\text { (3.3\% to } 18.7 \%)\end{array}$ & $\begin{array}{l}17.0 \% \\
\text { (3.1\% to } 31.0 \%)\end{array}$ \\
\hline Outcomes & $\begin{array}{l}-0.1 \% \\
(-1.5 \% \text { to } 1.3 \%)\end{array}$ & $\begin{array}{l}8.7 \% \\
(0.3 \% \text { to } 17.0 \%)\end{array}$ & $\begin{array}{l}0.07 \% \\
(-1.4 \% \text { to } 1.5 \%)\end{array}$ & $\begin{array}{l}9.07 \% \\
(-7.4 \% \text { to } 25.5 \%)\end{array}$ & $\begin{array}{l}12.5 \% \\
(-13.0 \% \text { to } 37.9 \%)\end{array}$ & $\begin{array}{l}9.3 \% \\
(-12.8 \% \text { to } 31.5 \%)\end{array}$ & $\begin{array}{l}12.9 \% \\
(-21.7 \% \text { to } 47.6 \%)\end{array}$ \\
\hline Costs & $\begin{array}{l}\$ 165.05 \\
(\$ 27.35 \text { to } \$ 302.76)\end{array}$ & $\begin{array}{l}-\$ 1593.10 \\
(-\$ 2699.70 \text { to } \\
-\$ 486.51)\end{array}$ & $\begin{array}{l}-\$ 217.26 \\
(-\$ 356.20 \text { to } \\
-\$ 78.32)\end{array}$ & $\begin{array}{l}-\$ 2896.69 \\
(-\$ 4756.70 \text { to } \\
-\$ 1036.68)\end{array}$ & $\begin{array}{l}-27.9 \% \\
(-40.9 \% \text { to }-15.0 \%)\end{array}$ & $\begin{array}{l}-\$ 3765.75 \\
(-\$ 6157.79 \text { to } \\
-\$ 1373.71)\end{array}$ & $\begin{array}{l}-34.2 \% \\
(-48.5 \% \text { to }-19.8 \%)\end{array}$ \\
\hline
\end{tabular}


A All patients

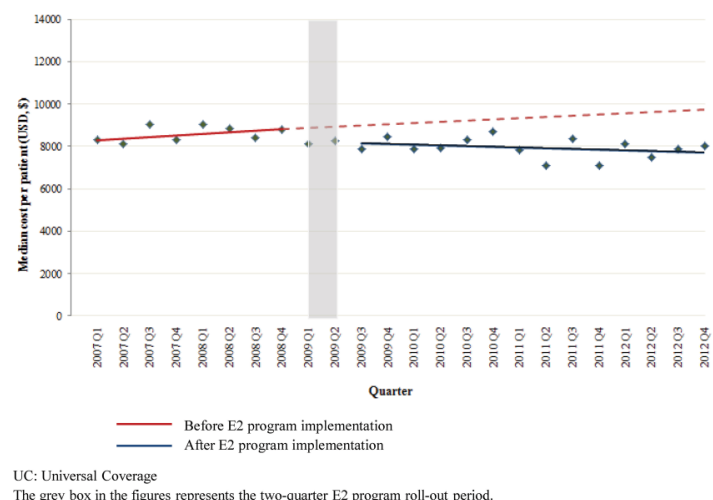

B UC patients

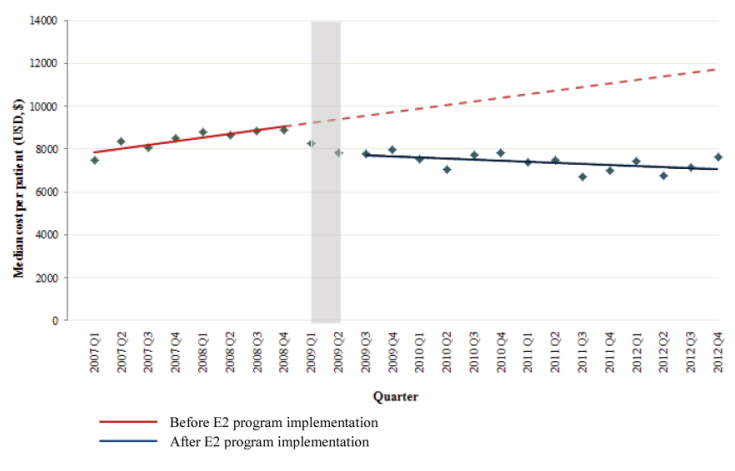

Figure 2 Incident use of E2 medicines among eligible patients, by quarter, 2007-2012.

respectively, relative to the proportion estimated without the programme (table 2). Figure 2B shows the percentage change of eligible UC patients receiving E2 medicines after the E2 program implementation. As NHSO implemented the E2 program for patients in the UC scheme in January 2009, relative utilisation of E2 medicines among UC patients increased significantly by almost $20 \%$ in year 1 and by $17 \%$ in year 2 (table 2 ).

\section{Clinical outcomes}

Figure 3A, B shows the percentages of eligible patients with eight selected indications who showed improvements of their acute conditions in the overall population and among UC patients, respectively. The proportion of patients with clinical improvements increased by $5.4 \%$ (95\% CI $2.0 \%$ to $8.7 \%$ ) immediately after the implementation of the E2 program. Although not statistically significant, the estimated proportions of patients with clinical improvements were $6.6 \%(95 \%$ CI $-1.9 \%$ to $15.1 \%)$ and $6.2 \%(-5.0 \%$ to $17.5 \%)$ higher at year 1 and 2 relative to the estimate proportion without the E2 program. For UC patients, the relative proportions of patients with improvements were $12.5 \% \quad(95 \%$ CI $-13.0 \%$ to $37.9 \%)$ and $12.9 \%(95 \%$ CI $-21.7 \%$ to $47.6 \%$ ) higher at 1 and 2 years.

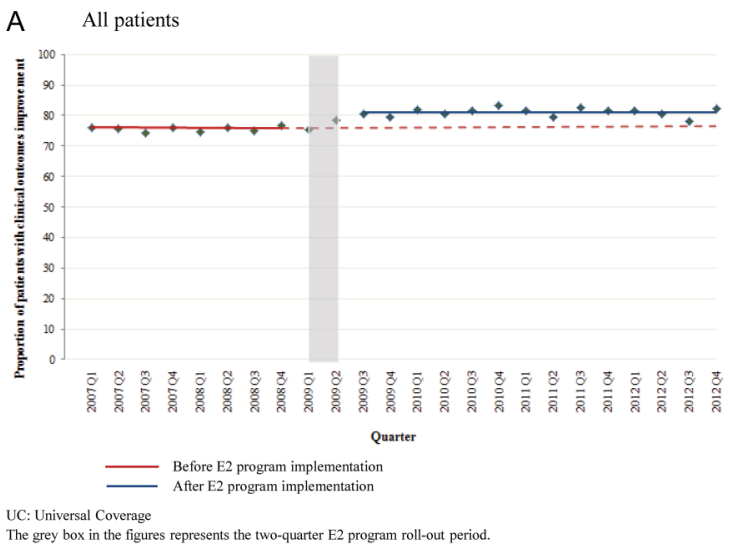

\section{Healthcare costs}

Figure 4A, B shows quarterly healthcare costs per patient. One year after implementation, the quarterly healthcare costs per patient were $13.5 \%$ lower (95\% CI $-26.9 \%$ to $-0.2 \%)$ than would have been expected without the E2 program for all eligible patients and $27.9 \%$ lower $(95 \%$ CI $-40.9 \%$ to $-15.0 \%$ ) for eligible UG patients. In the second year, quarterly costs per patient were $17.2 \%$ lower (95\% CI $-33.7 \%$ to $-0.7 \%$ ) than expected for all eligible patients and $34.2 \%$ lower (95\% CI $-48.5 \%$ to $-19.8 \%$ ) for eligible UC patients. Costs per patient continued to decrease during the first 2 years of programme implementation. These reductions resulted in quarterly healthcare cost savings of $-\$ 1253.66$ per patient for all patients and $-\$ 2896.69$ per patient for UC patients, respectively, at 1 year after the E2 program was implemented (table 2).

Table 3 shows annual healthcare costs per patient over the study period. Annual healthcare expenditures for patients eligible for E2 program medicines in the three hospitals decreased approximately $9.5 \%$ after the E2 program implementation.

\section{DISCUSSION}

Our findings show that the E2 program has been associated with an increasing number of patients receiving

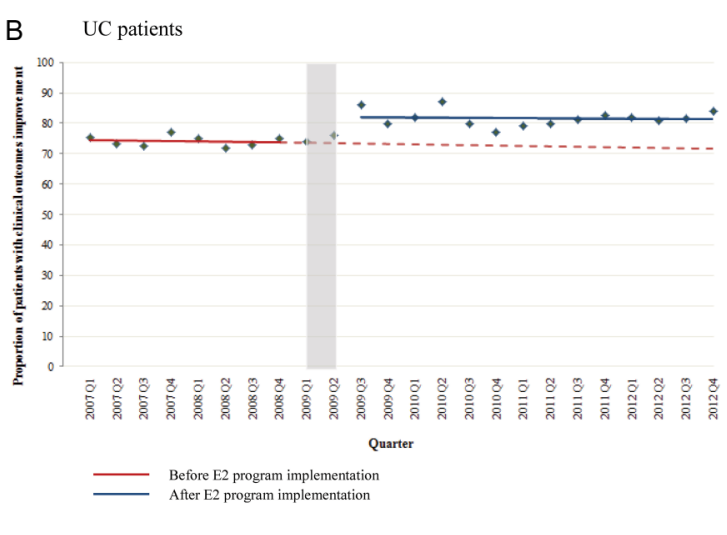

Figure 3 Proportion of eligible patients with improvements in clinical outcomes, by quarter, 2007-2012. 
A All patients

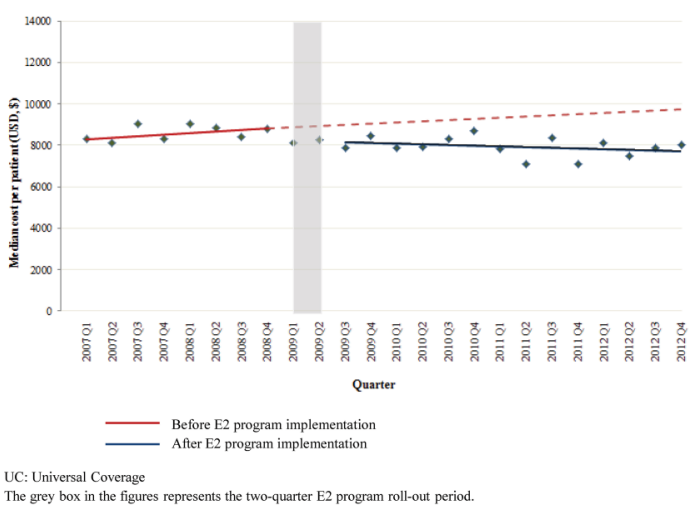

B UC patients



Figure 4 Median quarterly healthcare costs per patient among eligible patients, by quarter, 2007-2012.

specialty medicines, especially among UC patients who constitute the majority of the Thai population. It may have improved clinical outcomes. There were substantial decreases in both treatment costs per patient and annual health expenditures after policy implementation, mainly due to decreases in E2 medicines prices. We speculate that pooled procurement and special purchasing arrangements with companies resulted in lower prices. $^{22}$

In order to facilitate access to medicines under UHC, consideration of economic aspects is needed. ${ }^{23}$ Among patients receiving E2 medicines included in our study, cost of medicines accounted for approximately $73 \%$ of total healthcare costs before the E2 program. The increase in the number of patients receiving the specialty medicines following implementation of the E2 program could threaten financial sustainability. The sharp reduction in E2 medicine prices seems to have been a key factor in overcoming the financial barrier to purchasing the medicines for UC patients as the central purchasing mechanism implemented by NHSO and GPO in January 2009 decreased prices of E2 medicines by approximately $25 \%$ (range $8-40 \%),{ }^{24}$ allowing expanded medicines coverage while limiting spending increases.

Our study adds to what is known about policies to facilitate access to high-cost medicines. An earlier study evaluated operational aspects of the E2 program and healthcare professionals' perspectives about it. ${ }^{10}$ Most professionals agreed that the implementation of the E2 program would reduce hospital expenditures on medicines, particularly for UC patients. However, the study did not define high-cost medicines or criteria for prescribing them and nor did it monitor changes in clinical outcomes. Our study demonstrates that the E2 program achieved the intended objectives related to access and cost, and possibly the clinical outcomes in three tertiary care hospitals.

Programmes implemented for increasing access to high-cost medicines are mostly found in developed countries such as Canada, ${ }^{25-27}$ Australia, ${ }^{28}{ }^{29}$ England $^{30}$ and France, ${ }^{25}$ but few studies have evaluated such policies. ${ }^{28}{ }^{29}$ In low and middle income countries, ${ }^{31} 32$ policies aim to expand access to oncology medicines or medicines treating global health problems (HIV, malaria and tuberculosis) ${ }^{31} 32$ and their evaluations usually focus on the number of patients treated and clinical benefits. ${ }^{33-35}$ Our study covers those outcomes and assessed the policy impact on costs for the health system.

The strengths of our study include its longitudinal design, its use of clinical and cost data, and its focus on all three objectives of the E2 program-increased patient access, improved clinical outcomes and reduced cost. We ascertained treatment eligibility and changes in clinical outcomes based on explicit criteria specified by the E2 program, which were further confirmed by Thai clinical experts to reflect clinical practice in Thailand. To reflect the actual health system costs, we used E2 medicines prices from central purchasing for UC patients after the E2 program implementation.

Our study has several limitations. Since the intervention was implemented for all UC members at the same time, we had no suitable comparison group. However, we obtained data for 7 years, including 3 years before the programme. The interrupted time-series design enabled us to control for baseline levels and trends, accounting for major threats to internal validity, and to detect changes in the outcomes studied after the policy was implemented. ${ }^{18}$ Second, the generalisability of our results may be limited because we evaluated the policy impacts on utilisation and costs of 5 of the 10 medicines in the E2 program and clinical outcomes for 2 medicines based on data from three hospitals. Moreover, we did not have sufficient power to assess variations in outcomes across regions/hospitals due to a diverse population (different regions, different types of hospitals). However, hospitals were university hospitals in different regions (northern, central and capital city), representing potentially different treatment settings. Third, four medicines (docetaxel, letrozole, erythropoietin $\alpha$ and 
Table 3 Healthcare costs for patients eligible for E2 medicines by year, 2006-2012

\begin{tabular}{|c|c|c|c|c|c|c|}
\hline $\begin{array}{l}\text { Costs for patients eligible for } \\
\text { E2 medicines (median (IQR)) }\end{array}$ & 2007 & 2008 & 2009 & 2010 & 2011 & 2012 \\
\hline \multicolumn{7}{|c|}{ Annual healthcare expenditures ${ }^{*}$ (median (IQR)) } \\
\hline Total healthcare costs & $\begin{array}{l}\$ 67515 \\
(\$ 12592, \$ 218725)\end{array}$ & $\begin{array}{l}\$ 87706 \\
(\$ 12990, \$ 235668)\end{array}$ & $\begin{array}{l}\$ 55749 \\
(\$ 12990, \$ 235668)\end{array}$ & $\begin{array}{l}\$ 72184 \\
(\$ 16252, \$ 215144)\end{array}$ & $\begin{array}{l}\$ 65123 \\
(\$ 19521, \$ 263784)\end{array}$ & $\begin{array}{l}\$ 70275 \\
(\$ 22946, \$ 239868)\end{array}$ \\
\hline All medicines & $\begin{array}{l}\$ 54992 \\
(\$ 10648, \$ 150343)\end{array}$ & $\begin{array}{l}\$ 68572 \\
(\$ 21788, \$ 205104)\end{array}$ & $\begin{array}{l}\$ 44395 \\
(\$ 13716, \$ 120051)\end{array}$ & $\begin{array}{l}\$ 50522 \\
(\$ 16829, \$ 157273)\end{array}$ & $\begin{array}{l}\$ 49170 \\
(\$ 17773, \$ 143529)\end{array}$ & $\begin{array}{l}\$ 53037 \\
(\$ 9067, \$ 134231)\end{array}$ \\
\hline E2 medicines & $\begin{array}{l}\$ 50787 \\
(\$ 10327, \$ 127922)\end{array}$ & $\begin{array}{l}\$ 63862 \\
(\$ 21223, \$ 172328)\end{array}$ & $\begin{array}{l}\$ 40628 \\
(\$ 13346, \$ 104496)\end{array}$ & $\begin{array}{l}\$ 44931 \\
(\$ 14457, \$ 134761)\end{array}$ & $\begin{array}{l}\$ 44831 \\
(\$ 17363, \$ 119392)\end{array}$ & $\begin{array}{l}\$ 48176 \\
(\$ 8827, \$ 111810)\end{array}$ \\
\hline Non-E2 medicines & $\begin{array}{l}\$ 4410 \\
(\$ 283, \$ 23799)\end{array}$ & $\begin{array}{l}\$ 5173 \\
(\$ 321, \$ 22420)\end{array}$ & $\begin{array}{l}\$ 3410 \\
(\$ 369, \$ 17548)\end{array}$ & $\begin{array}{l}\$ 5387 \\
(\$ 371, \$ 22512)\end{array}$ & $\begin{array}{l}\$ 4219 \\
(\$ 409, \$ 24136)\end{array}$ & $\begin{array}{l}\$ 5186 \\
(\$ 565, \$ 25574)\end{array}$ \\
\hline Other costs & $\begin{array}{l}\$ 12250 \\
(\$ 2352, \$ 40202)\end{array}$ & $\begin{array}{l}\$ 20713 \\
(\$ 2341, \$ 45206)\end{array}$ & $\begin{array}{l}\$ 10657 \\
(\$ 1770, \$ 34254)\end{array}$ & $\begin{array}{l}\$ 21661 \\
(\$ 2786, \$ 64862)\end{array}$ & $\begin{array}{l}\$ 15963 \\
(\$ 2572, \$ 59841)\end{array}$ & $\begin{array}{l}\$ 16913 \\
(\$ 2175, \$ 61997)\end{array}$ \\
\hline \multicolumn{7}{|c|}{ Expenditures per patient* (median (IQR)) } \\
\hline Number of eligible patients & 273 & 301 & 315 & 362 & 371 & 402 \\
\hline Total healthcare costs & $\begin{array}{l}\$ 4180 \\
(\$ 2033, \$ 9100)\end{array}$ & $\begin{array}{l}\$ 4391 \\
(\$ 2323, \$ 8216)\end{array}$ & $\begin{array}{l}\$ 3192 \\
(\$ 1385, \$ 6250)\end{array}$ & $\begin{array}{l}\$ 3267 \\
(\$ 1340, \$ 6359)\end{array}$ & $\begin{array}{l}\$ 3361 \\
(\$ 1544, \$ 7085)\end{array}$ & $\begin{array}{l}\$ 3197 \\
(\$ 1248, \$ 6198)\end{array}$ \\
\hline All medicines & $\begin{array}{l}\$ 3326 \\
(\$ 1278, \$ 5959)\end{array}$ & $\begin{array}{l}\$ 3244 \\
(\$ 1899, \$ 6704)\end{array}$ & $\begin{array}{l}\$ 2314 \\
(\$ 1031, \$ 4830)\end{array}$ & $\begin{array}{l}\$ 2365 \\
(\$ 1092, \$ 4799)\end{array}$ & $\begin{array}{l}\$ 2389 \\
(\$ 1232, \$ 5168)\end{array}$ & $\begin{array}{l}\$ 2291 \\
(\$ 1175, \$ 5539)\end{array}$ \\
\hline E2 medicines† & $\begin{array}{l}\$ 3083 \\
(\$ 1081, \$ 4660)\end{array}$ & $\begin{array}{l}\$ 3193 \\
(\$ 1111, \$ 5233)\end{array}$ & $\begin{array}{l}\$ 2102 \\
(\$ 1031, \$ 4164)\end{array}$ & $\begin{array}{l}\$ 2180 \\
(\$ 1139, \$ 4300)\end{array}$ & $\begin{array}{l}\$ 2167 \\
(\$ 951, \$ 4108)\end{array}$ & $\begin{array}{l}\$ 2071 \\
(\$ 1081, \$ 4660)\end{array}$ \\
\hline Non-E2 medicines & $\begin{array}{l}\$ 314 \\
(\$ 50, \$ 911)\end{array}$ & $\begin{array}{l}\$ 311 \\
(\$ 64, \$ 784)\end{array}$ & $\begin{array}{l}\$ 254 \\
(\$ 49, \$ 856)\end{array}$ & $\begin{array}{l}\$ 196 \\
(\$ 49, \$ 700)\end{array}$ & $\begin{array}{l}\$ 266 \\
(\$ 43, \$ 808)\end{array}$ & $\begin{array}{l}\$ 220 \\
(\$ 40, \$ 741)\end{array}$ \\
\hline Other costs & $\begin{array}{l}\$ 854 \\
(\$ 269, \$ 1793)\end{array}$ & $\begin{array}{l}\$ 914 \\
(\$ 277, \$ 1554)\end{array}$ & $\begin{array}{l}\$ 878 \\
(\$ 158, \$ 1359)\end{array}$ & $\begin{array}{l}\$ 902 \\
(\$ 133, \$ 1442)\end{array}$ & $\begin{array}{l}\$ 980 \\
(\$ 133, \$ 1432)\end{array}$ & $\begin{array}{l}\$ 916 \\
(\$ 103, \$ 1330)\end{array}$ \\
\hline
\end{tabular}

*(US\$, year 2014 value)

$(\$ 158, \$ 1359)$

$(\$ 103, \$ 1330)$

†Central procurement prices were used to calculate costs of E2 medicines after policy implementation. 
erythropoietin $\beta$ ) were excluded from the evaluation because other programmes facilitating patient access had been implemented before the E2 policy. No co-interventions, which may have influenced the results, had been implemented for the study medicines at the time of the policy, allowing us to determine the impacts of the E2 program. Fourth, we limited the evaluation of clinical outcomes to eight acute conditions because our clinical experts suggested that outcomes of chronic conditions could not be evaluated in the relatively short follow-up period. Further evaluation will be needed to assess these outcomes. Clinical outcome changes at 1 and 2 years after the policy were not significant, potentially due to the diversity of conditions and outcomes and the relatively small numbers of patients affected. Fifth, an observer bias may occur during the chart review process because the chart reviewer could identify the E2 medicine treatment status of the patient. However, we reduced that bias by strictly following explicit clinical outcome criteria and the research nurses were not aware of the objective of the study. Lastly, we could not assess the impact of the E2 program for SSS members because it was not implemented for SSS members until 2012. However, the UC patients studied were the primary focus of the policy and constitute the majority of the Thai population.

In summary, the E2 program is an approach to facilitate patient access to high-cost specialty medicines in Thailand. The programme is expanding both in terms of the number of medicines covered and of the special purchasing arrangements between the government and companies to lower medicine prices. ${ }^{5}$ In 2014,12 products were added to the E2 list for 27 indicated conditions. ${ }^{36}$ In January 2013, the SWO transferred its budget to NHSO to participate in central procurement and delivery of E2 medicines for SSS patients. This will increase the NHSO's power to negotiate E2 medicines prices because it will arrange procurement for more than $90 \%$ of the Thai population. Ongoing national monitoring is needed to assess the intended and unintended quality of care, equity and economic effects of the E2 program. In addition to hospital expenditures, studies should examine the associated costs of inventory management, distribution, communication, training, programme implementation and patient monitoring, as well as the satisfaction of different stakeholders with the programme.

\footnotetext{
Author affiliations

${ }^{1}$ Department of Pharmacy Practice, Faculty of Pharmaceutical Sciences, Center of Pharmaceutical Outcomes Research, Naresuan University, Phitsanulok, Thailand

${ }^{2}$ Department of Population Medicine, Harvard Medical School and Harvard Pilgrim Health Care Institute, Boston, Massachusetts, USA

${ }^{3}$ Pharmaceutical Care Research Unit, Faculty of Pharmaceutical Sciences, Naresuan University, Phitsanulok, Thailand

${ }^{4}$ College of Pharmacy, South Dakota State University, Brookings, South Dakota, USA

${ }^{5}$ School of Pharmacy, Monash University Malaysia, Selangor, Malaysia

${ }^{6}$ School of Population Health, University of Queensland, Brisbane, Australia
}

${ }^{7}$ School of Pharmacy, University of Wisconsin-Madison, Madison, Wisconsin, USA

Acknowledgements The authors would like to thank the Drug Fund, National Health Security Office for suggesting the research question. They are thankful for the cooperation and participation of the physicians, pharmacists and other staff at the three hospitals at which data collection occurred. They gratefully acknowledge the support of Professor Dr Kongkiat Kulkantrakorn, Faculty of Medicine, Thammasat University, Dr Charungthai Dejthevaporn, Faculty of Medicine, Ramathibodi University, Professor Dr Ponlapat Rojnuckarin, Faculty of Medicine, Chulalongkorn University, and Professor Dr Suradej Hongeng, Faculty of Medicine, Ramathibodi University for their inputs into clinical criteria development.

Contributors All authors participated in the manuscript's conception and design, data analysis and data interpretation, take responsibility for the integrity of the work as a whole, and approved the final version for publication. RS, NC, AKW, TD, SN, CYL and DR-D designed the study. RS did the statistical analyses. AKW, CYL and DR-D provided comments related to methodology and analysis plan. RS and NC wrote the article and all authors revised it critically for important intellectual content. RS and NC acquired the data; they had full access to all the data in the study and take responsibility for the integrity of the data and the accuracy of the data analysis. TD and SN provided comments related to the context of Thailand. All the authors had final responsibility for the decision to submit for publication.

Funding The Thailand Research Fund through the Royal Golden Jubilee PhD program (grant number PHD/0127/2552 to RS), the National Health Security Office and the Harvard Medical School Fellowship in Pharmaceutical Policy Research supported Dr Rosarin Sruamsiri in conducting this research.

Disclaimer The funder of the study had no role in the study design, data collection, data analysis, data interpretation or writing of the report.

Competing interests None declared.

Ethics approval The Ethics Committee of Naresuan University and the hospitals approved the study protocol (ID 550104 0041).

Provenance and peer review Not commissioned; externally peer reviewed.

Data sharing statement Data available on request, at the approval of studied.

Open Access This is an Open Access article distributed in accordance with the Creative Commons Attribution Non Commercial (CC BY-NC 4.0) license, which permits others to distribute, remix, adapt, build upon this work noncommercially, and license their derivative works on different terms, provided the original work is properly cited and the use is non-commercial. See: http:// creativecommons.org/licenses/by-nc/4.0/

\section{REFERENCES}

1. Pan American Health Organization. Access to high-cost medicines in the Americas: situation, challenges and perspectives. Washington DC: Area of Technology, Health Care and Research, Essential Medicines and Biologicals Unit (THR/EM), 2010.

2. Office of the National Economic and Social Development Board. Thailand Health expenditure 2002-2013. Secondary Thailand Health expenditure 2002-2013. 2013. http://social.nesdb.go.th/SocialStat/ StatReport_Final.aspx? reportid $=256 \&$ template $=1$ R2C\&yeartype $=$ M\&subcatid $=18$

3. Bureau of Policy and Strategy; Ministry of Public Health. Thailand health profile report 2008-2010. Bangkok: Bureau of Policy and Strategy, Ministry of Public Health, 2007.

4. Kalo Z, Inotai A, Merész G. PHP44 international comparison of pharmaceutical expenditure in middle income countries: methodological questions. Value Health 2012;15:A21.

5. The National Health Security Office. Quarterly annual report. Nonthaburi, 2013.

6. Thailand's Universal Coverage Scheme: Achievements and Challenges. An independent assessment of the first 10 years (20012010). Nonthaburi, Thailand: Health Insurance System Research Office, 2012.

7. Sakunphanit T. Universal health care coverage through pluralistic approaches: experience from Thailand. Asian Decent Work Decade: 
Internaltional Labour Organization Subregional Office for East Asia, 2006.

8. Yoongthong W, Hu S, Whitty JA, et al. National drug policies to local formulary decisions in Thailand, China, and Australia: drug listing changes and opportunities. Value Health 2012;15(Suppl 1): S126-31.

9. National Drug Committee. National List of Essential Medicines 2008 Nonthaburi: Ministry of Public Health, 2008.

10. Turongkaravee S, Rattanavipapong W, Khampang R, et al. Evaluation of high-cost medicine scheme (category E2) under the 2008 National List of Essential Medicines. Nonthaburi: Health Intervention and Technology Assessment Program, 2012.

11. National Health Security Office. Annual report 2012. Bangkok: National Health Security Office, 2012.

12. Sruamsiri R, Ross-Degnan D, Lu CY, et al. Policies and programs to facilitate access to targeted cancer therapies in Thailand. PLOS ONE 2015;10:e0119945.

13. Jacobs B, Ir Por, Bigdeli M, et al. Addressing access barriers to health services: an analytical framework for selecting appropriate interventions in low-income Asian countries. Health Policy Plan 2012;27:288-300.

14. Ministry of Public Health Network of Unit Cost. Unit Cost Manual for Hospital: Nonthaburi, Thailand MUCC. 2011.

15. Bank of Thailand. Exchange rate. Secondary Exchange rate 2014. http://www2.bot.or.th/statistics/BOTWEBSTAT.aspx? report|D=145\&language $=\mathrm{TH}$

16. Bank of Thailand. EC_EI_027: Thailand's Macro Economic Indicators 1. Secondary EC_EI_027: Thailand's Macro Economic Indicators 1. 2014. http://www2.bot.or.th/statistics/ReportPage.aspx? report $\mid \mathrm{D}=409$ \&language $=$ eng

17. Ministry of Public Health Thailand. Drug Medical Supply and Information Center (DMSIC). Secondary Drug Medical Supply and Information Center (DMSIC). http://dmsic.moph.go.th/price.htm

18. Shadish W, Cook T, Campbell D. Experimental and quasiexperimental designs for generalized causal inference. Boston: Houghton Mifflin Company, 2002.

19. Box GEP, Jenkins GM, Reinsel GC. Time series analysis forecasting and control. 4th edn. San Francisco: Holden-Day, 1976.

20. Wagner AK, Soumerai SB, Zhang F, et al. Segmented regression analysis of interrupted time series studies in medication use research. J Clin Pharm Ther 2002;27:299-309.

21. Zhang F, Wagner AK, Soumerai SB, et al. Methods for estimating confidence intervals in interrupted time series analyses of health interventions. J Clin Epidemiol 2009;62:143-8.

22. Thai working group on National Health Account. The report on 1994-2008 National Health Expenditure. Nonthaburi: International Health Policy Program, Ministry of Public Health, 2010.
23. World Health Organization. The world health report 2010, health system financing: the path to universal coverage. Geneva: World Health Organization, 2010.

24. Government Pharmaceutical Organization. Report of central procument of E2 medicines 2009-2012. Bangkok: Government Pharmaceutical Organization (GPO), 2013.

25. Athanasios N, Ellen N, Nicholas M. Paying for (expensive) drugs in the statutory system: an overview of experiences in 13 countries. London: London School of Hygiene and Tropical Medicine, 2008.

26. Ministry of Health and Long-Term Care Ontario Drug Benefit. Exceptional Access Program (EAP). Secondary Exceptional Access Program (EAP). 2014. http://www.health.gov.on.ca

27. Ministry of Health. Limited Coverage Drugs Program. Secondary Limited Coverage Drugs Program. 2012. http://www.health.gov.bc.ca

28. Lu CY, Macneill $\mathrm{P}$, Williams $\mathrm{K}$, et al. Access to high cost medicines in Australia: ethical perspectives. Aust New Zealand Health Policy 2008;5:4.

29. Lu CY, Williams K, Day R. The funding and use of high-cost medicines in Australia: the example of anti-rheumatic biological medicines. Aust New Zealand Health Policy 2007;4:2.

30. The Department of Health. The Cancer Drugs Fund: guidance to support operation of the Cancer Drugs Fund in 2011-12. Secondary The Cancer Drugs Fund: guidance to support operation of the Cancer Drugs Fund in 2011-12. http://www.elmmb.nhs.uk

31. Cardoso SW, Luz PM, Velasque L, et al. Effectiveness of first-line antiretroviral therapy in the IPEC cohort, Rio de Janeiro, Brazil. AIDS Res Ther 2014;11:29.

32. Wolff MJ, Cortés CP, Shepherd BE, et al. Long-term outcomes of a national expanded access program to antiretroviral therapy: the Chilean AIDS cohort. J Acquir Immune Defic Syndr 2010;55:368-74.

33. Samuels BL, Chawla S, Patel S, et al. Clinical outcomes and safety with trabectedin therapy in patients with advanced soft tissue sarcomas following failure of prior chemotherapy: results of a worldwide expanded access program study. Ann Oncol 2013;24:1703-9.

34. Tekinturhan E, Audureau E, Tavolacc MP, et al. Improving access to care in low and middle-income countries: institutional factors related to enrollment and patient outcome in a cancer drug access program. BMC Health Serv Res 2013;13:304.

35. Capdeville R, Krahnke T, Hatfield A, et al. Report of an international expanded access program of imatinib in adults with Philadelphia chromosome positive leukemias. Ann Oncol 2008;19: 1320-6.

36. National Drug Committee. National List of Essential Medicines 2014 Secondary National List of Essential Medicines 2014. 2014. http:// drug.fda.moph.go.th:81/nlem.in.th/medicine/essential/list 